\title{
Informal planning: a tool towards adaptive urban governance
}

\author{
Theodora PAPAMICHAIL, ETH Zurich, Institute of Spatial and Landscape Development; \\ Switzerland \\ Ana PERIĆ, ETH Zurich, Institute for Spatial and Landscape Development; Switzerland; \\ University of Belgrade, Faculty of Architecture; Serbia
}

\begin{abstract}
Formal planning instruments and procedures have often been unpopular and ineffective for solving complex spatial issues, such as urban sprawl or transport congestion. As a result, such conflicts turn into complex planning tasks that usually exceed the provisioned time and funding, especially when faced with adversarial interests of actors from different organisations, sectors or social groups. Hence, informal planning, as a non-binding supplement to official planning instruments, is often considered highly effective. In its broadest sense, informal planning includes the principles of collaborative dialogue, diverse networks, trustful relationships and tailor-made processes among interested parties. Consequently, informal planning processes foster sound decision-making delivering a spectrum of problem-oriented solutions and increasing public consensus, while enacting experimentation, learning, change, and the creation of shared meanings among stakeholders. However, informal planning cannot be taken for granted - it is strongly interwoven with the planning culture influenced by the historical and political background, and the current socio-economic conditions.
\end{abstract}

This paper revolves around several pillars. After an introductory section, a brief historical overview firstly identifies the place of informal planning in various planning models that have appeared since the 1960s. More specifically, informal planning is analysed against the theoretical concept of collaborative rationality. Finally, the paper focuses on a specific informal planning procedure called the 'test planning method', being analysed against the previously elaborated theoretical background. As this instrument links both formal and informal planning, its comparison and interrelation with the theoretical background of collaborative rationality contributes to elucidating the following attributes of adaptive (collaborative) urban governance: 1) flexible and agile institutional arrangements supportive to various kinds of urban planning mechanisms (not only official tools), 2) proactive and imaginative planners ready to accept solutions created outside the technical domain of instrumental rationality, and 3) inclusion of numerous stakeholders to exchange various information and different types of knowledge, i.e. expert and experiential knowledge. Observed through the example of the test planning method, the article finally highlights the successful aspects of informal planning, however, pointing also to its shortcomings, which could be expected in the societies with a lack of key democratic elements.

\section{Keywords}

Informal planning, adaptive urban governance, collaborative rationality, test planning method. 


\section{Introduction: challenges of formal planning}

In recent years, global socio-economic transformations have strongly challenged the spatial planning practice. An indicative example refers to the countries of Eastern and Southern Europe, which in particular have experienced a prolonged economic crisis with tremendous impact on numerous facilities, services, and infrastructures. Increasing demand for housing, the provision of low-interest mortgages, and the significant, but not sustainable investments in major urban projects manifest the crisis unevenly across space (Papaioannou and Nikolakopoulou, 2016). In late 2009, international financial markets collapsed stranding millions of new owners with speculative debt few could sustain. The results were catastrophic, especially for southern economies, generating a prolonged recession. Massive state-financed rescue and recapitalisation of the financial system staved off complete collapse. Concerning, for instance, infrastructure management, national (and regional/local) governments have borrowed to fund infrastructure that encouraged such inefficient development - i.e. building roads for unsustainable sprawling development rather than trains for compact sustainable development (Zifou, 2015).

Taking into consideration the discussed socio-economic challenges, current spatial problems in such environments flow from the complexity of decision-making among hierarchical levels of political and economic competition among private firms (developers, lenders, investors, land owners), households (owners, renters), political organizations (political parties, advocacy groups, non-profits) and public officials (elected, administrators, professionals) (Papamichail and Perić, 2018). All these agents make plans, but the ensuing decisions are neither transparent nor coordinated. Legal and regulatory arrangements of spatial planning context usually fail to bring at the same table all the actors who are respectively responsible in decision-making, or provide effective feedback and controlling mechanisms against fasttrack investments or uncontrolled privatization of public land and infrastructure. This results in, not only in exclusive benefits, but it also reflects to uneven spatial development across Europe, strengthening the dipole of the North-South. Despite the cohesion policies and tools of EU, countries with partially developed culture in collaboration have a different rhythm of adoption of such cohesion instruments than countries with an integral approach in spatial planning. Therefore, the question comes which informal supplements are appropriate to boost joint responsibility and support weak formal planning systems.

Briefly put, informal planning activities sacrifice authority for joint responsibility. Instead of focusing on actions of control, informal planning focuses on those whose actions shape the future consequences of spatial development (e.g., the flooding, the traffic, etc.), as well as those who will bear most of these consequences (Papamichail and Perić, 2018). Current formal planning structures usually limit people in these respective social positions and locations apart. On the contrary, informal action brings some of these people together and creates alliances in order collaborate towards making plans and setting directions of spatial development. Formal planning processes are usually trapped between political elections and the competition of economic investment. The informal approach invites politicians and investors to join in temporary collaboration beyond the restriction of formal roles. The collaboration is democratic and focused on deliberation among these participants. The 
payoff is not increased power, but purposeful criticism on reciprocal learning processes to conceive and compare problems and solutions for a place that combines causal assessment and political judgment (Briassoulis, 1997; Scholl, 2017; Papamichail and Perić, 2018).

The paper starts with focusing on the notion of informal planning and its supplementary role to the formal system, as well as its cognitive and practical contributions. This is followed by a brief overview of the main planning models in order to determine which of these contain the elements immanent to informal planning. The principles of collaborative rationality are particularly highlighted as they serve as a sound conceptual background for the informal planning practice. To be more specific, the next section describes the test planning method as a link between formal and informal planning and how it put those principles in practice. The concluding sections outline the main principles of informal planning and how they support adaptive urban governance, while they interpret the effectiveness of the informal approach arguing that informality works best for complex problems that formal systems fail to face.

\section{Informal planning}

\subsection{The notion of informal planning}

Informal processes are also referred to in the literature as: "nonstandard, underground, illegal, hidden, shadow, unobserved, submerged, irregular, invisible, unofficial, parallel, silent, alternative, paraplanning, opaque planning, shadow state" (Briassoulis 1997). Some of these terms indicate that, in the beginning, informality was connected to poverty and marginality. The informal sector was firstly introduced into international literature by the report of the International Labour Office Employment Mission in 1972, Kenya (Lubell 1991; Briassoulis 1997). The physical implications of informal activities have been analysed extensively and prove how informal systems provide everyday practices, illustrating cases such as squatter settlements in developing countries (Briassoulis 1997).

In a broader context nowadays, the term informal mainly relates to the non-institutionalised planning activities carried out either as a preliminary phase that supplements the formal planning process (Scholl, Staub and Vinzens 2013; Hoch, Scholl 2018) or as collaboration completely overlapping with formal planning (Briassoulis 1997). Therefore, it is of utmost importance to arrive at a better explanation of the concept of informal planning through its relation to formal planning. Briassoulis (1997) defines the three main criteria on the basis of the causes of informal planning: 1) degree of state regulation, 2) demand for planning, and 3) cost of planning. When mutually combined, these shows that informal planning appears whenever there is low state regulation but high demand for planning (e.g. in transitional societies driven by market demands). In cases where, on the one hand, there is weak state planning and low planning costs but also where state regulation is fully enforced but costs of planning are high (e.g. great infrastructural projects demanding additional resources to the available public ones), informal planning comes to the fore. Similar to the latter, high demand accompanied by high costs of planning provides room for informal planning activities (Papamichail, 2019). 
It is hard to argue over a precise definition since 'informality' meets a broader spectrum of criteria, as mentioned before, and according to Schönwadt (2008) there is no planning "per se"; he notes that: "Planning is always carried out by people who possess specific biological and psychological idiosyncrasies, who nearly always interact with organizations or cooperative projects, who live and work in their own social and cultural milieu, and who have certain aptitudes, skills, and shortcomings, which is to say restrictions", while, based on the view of Tewdwr-Jones and Allmendinger $(2002,214 \mathrm{f})$, he goes on to argue that "there is not one dominant paradigm in planning today..." dismissing the idea that the collaborative/communicative approach is the only approach to planning alive today. Hence, taking into consideration the shift in planning models explained previously, the degree of state regulation places the emphasis on the role of planners as public officials and their relationship to the activities of other stakeholders. More precisely, defining, on the one hand, the position of planners in the decision-making arena and, on the other, their link to non-public sector actors (civic society, individuals, interest groups) elucidates the roots of informal planning in a number of models, which appeared as a reaction to the rational planning.

Briefly, informal planning concerns non-institutionalised processes that supplement the formal institutional practice, increasing joint responsibility between actors. Informal planning through temporary and provisional processes deals with spatial conflicts that formal planning processes fail to fulfil. This does not mean that informal planning processes overlap or disregard formal planning frameworks, but that they supplement them in order to enable actors to communicate, cooperate and coordinate planning tasks between different institutional levels and sectors (Hoch and Scholl 2018), thus dealing with complexity and uncertainty in practice.

\subsection{The evolution of informal planning}

The rise of informality and the causal complexity of structural problems is related to the shift between first and second generation planning models. Instrumental rationality in planning emerged through the movement of Positivism in the 19th century, which aimed at applying the achievements of science and technology - however crude - to policy-making (Faludi, 1973). Therefore, on the basis of the following steps towards planning tasks, the rational model has been claimed as being too positivistic, ahistorical, and most of all, apolitical: (a) Analysis of the situation, (b) setting of goals, (c) formulation of possible courses of action to achieve those goals, and (d) a comparison of the consequences of each course of action (Meyerson and Banfield, 1964; Muller, 1993; Schönwandt, 2008). This planning model has also been characterised by its top-down approach, supporting the implementation of policies ignoring the public interest and social differences.

By the early 1970s, many analysts had begun to question not only the efficacy of the rational model in planning, but the possibility of the rational planning model in total, turning from technical to collaborative rationality and accepting uncertainty in planning (Hoch 1994). This 
critical perspective for the first-generation model was introduced by various scholars such as Lindblom, Forester, Rittel, Heally, Innes, etc. Later it was Rittel who contrasted the "first generation" model in planning with that of the "second generation". In particular, Rittel and Weber (1973) highlighted the importance of societal problems and dilemmas in planning in a different perspective from that of planning as an applied science:

"A great many barriers keep us from perfecting such a planning/governing system: theory is inadequate for decent forecasting; our intelligence is insufficient to our tasks; plurality of objectives held by pluralities of politics makes it impossible to pursue unitary aims; and so on. $[\ldots]$

The kinds of problems that planners deal with - societal problems - are inherently different from the problems that scientists and perhaps some classes of engineers deal with. Planning problems are inherently wicked." (p.160)

The theoretical approach of the so-called "wicked" problems brought various changes in planning theory. The questioning towards the rational model of planning resulted in six planning models that followed: the advocacy model, the (neo) Marxist model, the model of equity planning, the radical model, the liberalistic model of planning, and the collaborative/communicative model (also referred as the model of social learning and communicative action). Figure 1 illustrates the main representatives and objectives of each planning model. The theory of 'communicative action' of Habermas has been criticised as to the basic conditions framing this conversational context as "ideal speech", which in turn set some constraints for planning in practice since there is no space free of power (Flyvbjerg, 1998, Schönwandt, 2008). Based on the Habermas' (1984) theory of communicative action, the work by collaborative planning scholars provides an empirically tested assessment of collaborative rationality: cooperation among numerous stakeholders, obtaining valid information, and exchange of information and different types of knowledge - expert and experiential (Booher and Innes, 2002; Forester, 1989, 1999; Healey, 1992, 1995; Innes, 1995; Sandercock, 1998).

\begin{tabular}{|c|c|c|c|c|c|c|}
\hline $\begin{array}{l}\text { RATIONAL } \\
\text { MODEL OF } \\
\text { PLANNING }\end{array}$ & $\begin{array}{l}\text { ADVOCACY } \\
\text { MODEL OF } \\
\text { PLANNING }\end{array}$ & $\begin{array}{l}\text { NEO- } \\
\text { MARXIST } \\
\text { MODEL OF } \\
\text { PLANNING }\end{array}$ & $\begin{array}{l}\text { THE EQUITY } \\
\text { MODEL OF } \\
\text { PLANNING }\end{array}$ & $\begin{array}{l}\text { RADICAL } \\
\text { MODEL } \\
\text { OF } \\
\text { PLANNING }\end{array}$ & $\begin{array}{l}\text { LIBERALISTIC } \\
\text { MODEL OF } \\
\text { PLANNING }\end{array}$ & $\begin{array}{l}\text { COLLABORATIVE/ } \\
\text { COMMUNICATIVE } \\
\text { MODEL OF } \\
\text { PLANNING }\end{array}$ \\
\hline Before 1960s & Mid 1960s & $\begin{array}{l}\text { End of 1960s- } \\
\text { mid 1970s }\end{array}$ & $1960 s$ & $1980 s$ & $1980 s$ & 1970s-1980s \\
\hline \multirow{6}{*}{$\begin{array}{l}\text { Meyerson } \\
\text { Banfield } \\
\text { Faludi }\end{array}$} & Davidoff & Lefebvre & Krumholz & Grabow & Sorensen & Habermas \\
\hline & \multirow{5}{*}{ Reiner } & \multirow{5}{*}{ Castells } & \multirow[t]{5}{*}{ Mier } & \multirow{5}{*}{ Heskin } & \multirow{5}{*}{ Day } & Forester \\
\hline & & & & & & Friedmann \\
\hline & & & & & & Healey \\
\hline & & & & & & Innes \\
\hline & & & & & & Hillier \\
\hline
\end{tabular}




\begin{tabular}{|c|c|c|c|c|c|c|}
\hline $\begin{array}{l}\text { Positivistic, } \\
\text { ahistorical, } \\
\text { apolitical } \\
\text { model of } \\
\text { planning. } \\
\text { "Top-down" } \\
\text { approach } \\
\text { supporting the } \\
\text { implementation } \\
\text { of policies } \\
\text { ignoring the } \\
\text { public interest } \\
\text { and social } \\
\text { differences. }\end{array}$ & $\begin{array}{l}\text { The "Public" } \\
\text { is not taken } \\
\text { for granted in } \\
\text { contrast with } \\
\text { the politically } \\
\text { "top-down" } \\
\text { approach of } \\
\text { rational } \\
\text { planning. }\end{array}$ & $\begin{array}{l}\text { Planning } \\
\text { becomes an } \\
\text { instrument of: } \\
\text {-Rationalisation } \\
\text { and } \\
\text { legitimatization } \\
\text { - Negotiation } \\
\text { and mediation } \\
\text { between the } \\
\text { differing } \\
\text { demands of } \\
\text { various groups. } \\
\text {-Regulator or } \\
\text { valve for the } \\
\text { pressure and } \\
\text { protest of the } \\
\text { governed } \\
\text { classes. }\end{array}$ & $\begin{array}{l}\text { The city } \\
\text { administration } \\
\text { is an arena in } \\
\text { which a } \\
\text { political } \\
\text { agenda is } \\
\text { debated, and } \\
\text { planners act in } \\
\text { favor of the } \\
\text { interests of } \\
\text { the } \\
\text { disadvantaged } \\
\text { within this } \\
\text { arena. }\end{array}$ & $\begin{array}{l}\text { Planners } \\
\text { become the } \\
\text { free-lancers, } \\
\text { acting } \\
\text { outside the } \\
\text { system and } \\
\text { identify } \\
\text { themselves } \\
\text { with the } \\
\text { unprivileged } \\
\text { social } \\
\text { groups, } \\
\text { usually living } \\
\text { and working } \\
\text { with them in } \\
\text { the deprived } \\
\text { areas. }\end{array}$ & $\begin{array}{l}\text { The market as } \\
\text { the main } \\
\text { regulator of } \\
\text { spatially } \\
\text { relevant } \\
\text { activities, } \\
\text { therefore the } \\
\text { market- } \\
\text { oriented } \\
\text { instruments can } \\
\text { be seen as a } \\
\text { means of } \\
\text { informal } \\
\text { planning } \\
\text { conducted by } \\
\text { the private } \\
\text { sector actors. }\end{array}$ & $\begin{array}{l}\text { The power of } \\
\text { knowledge and } \\
\text { learning was favored. } \\
\text { Planners involve the } \\
\text { "public" } \\
\text { (stakeholders and } \\
\text { inhabitants) by } \\
\text { incorporating their } \\
\text { knowledge and } \\
\text { abilities diminishing } \\
\text { the power of official } \\
\text { authorities and } \\
\text { providing equity } \\
\text { between responsible } \\
\text { 'players'. }\end{array}$ \\
\hline
\end{tabular}

Figure 1 - Seven models of planning (Source: T. Papamichail 2019, based on Schönwandt 2008).

Briefly put, the preliminary outlines of informal planning can be found in four planning models: advocacy, radical, liberal, and collaborative planning. In the advocacy planning model, the planners step out of the main planning boards, councils and committees in order to objectively represent the disadvantaged social groups and their interest. The public interest is not taken for granted; on the contrary, it must be defined through assessing the needs of the weaker parties (Davidoff \& Reiner 1962). The radical model follows this line of thought; however, it goes a step further. Planners become the freelancers, acting outside the system and identifying themselves with the underprivileged social groups, usually living and working with them in the deprived areas (Heskin 1980). The liberal planning model emphasises the role of the market as the main regulator of spatially relevant activities; therefore, the market-oriented instruments can be seen as a means of informal planning conducted by the private sector actors (Sorensen 1983). Finally, the collaborative planning ${ }^{1}$, ideologically based on the power of knowledge (be this expert and/or experiential) and good argument, diminishes the official authorities and makes all the stakeholders relevant and equal players in the game. A collaborative approach combining professional knowledge about spatial causes and consequences with the diverse interests and ideas of various stakeholders can be understood as informal planning, particularly within the emerging and transitional democracies.

\footnotetext{
${ }^{1}$ Many different terms revolving around the same idea of unhampered collaboration have appeared in recent decades: 'communicative-argumentative turn in planning' (Forester, 1989), 'planning through discussion and cooperation' (Healey, 1992), 'communicative planning' (Sager, 1994), 'pragmatic approach' (Hoch 1994), 'inclusive discourse' (Healey, 1995), 'communicative action and interactive practice' (Innes 1995), 'planning through consensus building' (Innes, 1996), 'collaborative planning' (Healey 1997), 'discursive practice' (Sandercock, 1998), 'deliberative planning' (Forester, 1999), etc. (Perić and Soltaniehha, 2015).
} 


\subsection{Collaborative rationality}

Innes and Booher (2010) further argue for the relevance of informal planning based on collaborative rationality in the context of complex spatial problems. They elaborate five principles to use to judge if and when to collaborate.

- Diversity and interdependence. Interdependence among diverse actors motivates participation and spreads risk and reward as each contributes to joint conceptions of problem and solution. Learning about mutual gains and risks encourages commitment to joint action now within an encompassing framework as future commitments remain provisional - open to changing circumstances and shifting participants.

- Collaborative dialogue, trust and knowledge. Collaborative dialogue among participants in small groups requires that each listen and learn from each other. Focusing on interests and intentions fosters trust as it informs judgments about causality and possibility. Future consequences replace attachment to rules and positions.

- Networks. Networks among the stakeholders include a wide variety of possible interrelationships. This may include interdisciplinary cooperation, i.e. cooperation among various sectors within administrative structure, but also intersectoral cooperation, which includes mutual activities across public, private and civil sectors.

- Monitoring and feedback. Accountability and responsibility animates the entire plan from the outset. Evaluation accompanies every phase because the plan provides an ongoing guide for relationships and not a blueprint.

- Small, diverse working groups. Convening small temporary groups of people with a stake in a pressing complex spatial problem makes it possible to build relationships tied to resolving the problem. People are more willing to trust others and reconsider old habits in the context of relationships tied to shared purpose yet provisional and sensitive to impacts for others.

Based on the Habermas' (1984) theory of communicative action, the work by collaborative planning scholars provides an empirically tested assessment of collaborative rationality: cooperation among numerous stakeholders, obtaining valid information, and exchange of information and different types of knowledge - expert and experiential (Booher \& Innes, 2002; Forester, 1989, 1999; Healey, 1992, 1995; Innes, 1995; Sandercock, 1998). Hence, how the principles of collaborative rationality relate with the deliverables of informal planning? The informal system taps the insight of diverse social experience to improve practical judgments about complex problems. Planning in such settings embraces the conventions of deliberative democracy linking small group discourse with scientifically informed causal and interpretive analysis of problems and solutions (Papamichail and Perić, 2018). 


\section{Test planning method: between formal and informal planning}

Numerous informal - or, as often called, 'collaborative' - planning processes have been developed; however, the one described below, the Test Planning Process, is based on the Action-Oriented Planning approach (Scholl, 1995) and it links formal and informal responsibility. More specifically, the Test Planning Process (TPP) is the informal planning method for creating concrete and feasible proposals and solving challenging tasks in spatial planning. It stimulates a critical discourse about implementing the solutions for complex and long-term spatial problems (Scholl et al., 2013, Scholl 2017). Instead of traditional/formal spatial planning methods, the TPP implies a collaborative process among numerous stakeholders with different interests, which combines top-down with bottom-up approaches. More than a common competition, the TPP gathers competitive ideas from various planning teams coordinated by an interdisciplinary steering committee. The resulting contributions are introduced, discussed and, after close evaluation, presented to an executive committee for further elaboration and implementation (Scholl et al., 2015; Papamichail, 2015).

According to Scholl et al. (2013), there are seven key theoretical principles underpinning test planning as a method:

- Concurrence of ideas. The core of test planning is the competition between various ideas. As a result, the most efficient solution is given to the contractor within the framework of the given conditions.

- Rhythm. Ideas and solutions mature due to repeated discussions and continuous testing throughout regularly scheduled meetings.

- No 'winner'. Unlike a traditional competition, there are no unique winning proposals. Since complex tasks often do not have ideal solutions, this method examines the different ideas of the teams and selects those that are most appropriate.

- Ad hoc organization. Test planning is an independent process and even the contributions of local and regional officials are considered according to the TPP rules. As a result, alternative, impartial solutions can emerge.

- Communication. Test planning cases are usually about areas whose future has a strong public interest. To gain public support for the results and attract various actors, communication and marketing of the various steps and solutions is important from the beginning.

- Finding problems and solutions. Apart from the final solutions, a redefinition or identification of new problems in addition to the given ones often takes place. This turns test planning into a dynamic process.

- 'Protected' process. Ideas and solutions are first discussed and tested in closed meetings between the teams and the steering committee before any public announcements in order to develop strong argumentation for the solution, and which paves the way for fruitful dialogue with various actors and the public to follow. 
A typical organisation and structure of the Test Planning Process is indicated in Figures 2 and 3.

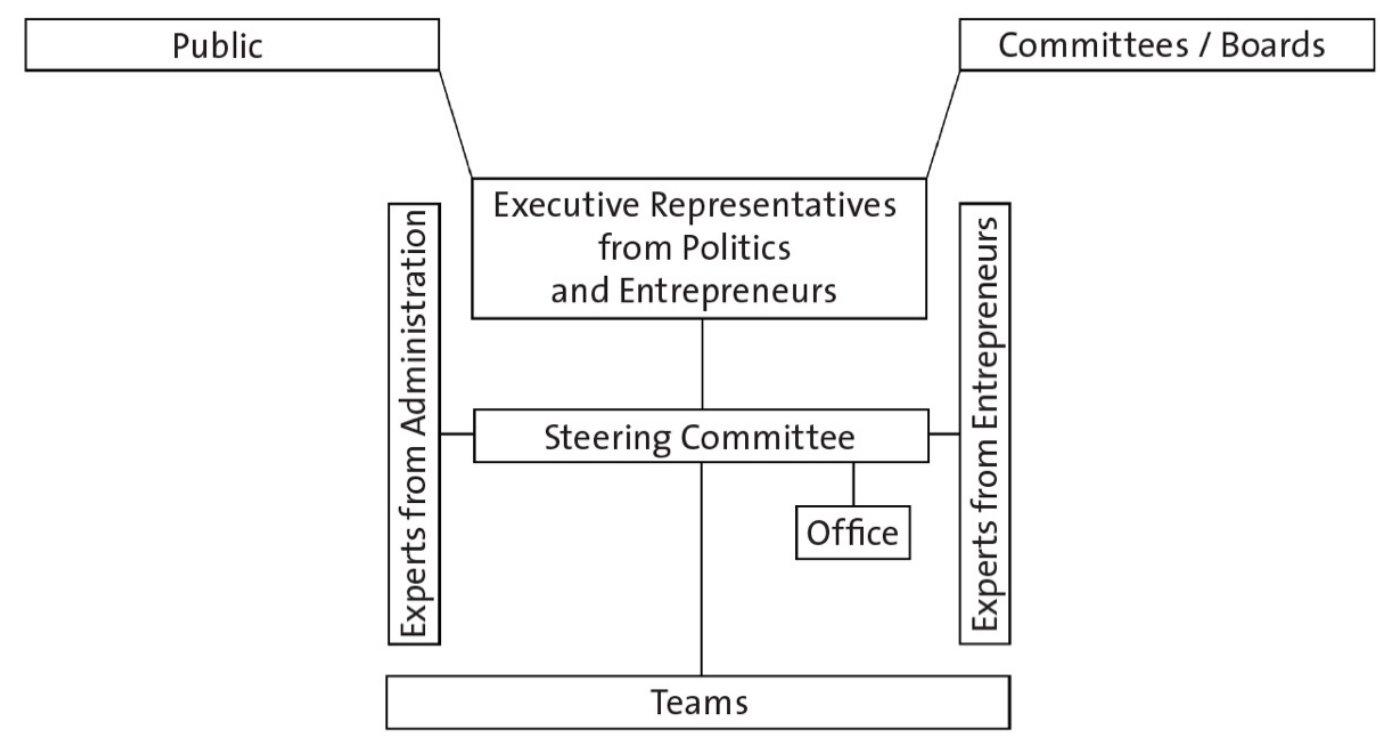

Figure 2 - Typical structure of a test planning process (Source: ARL 2011 in Scholl 2017).

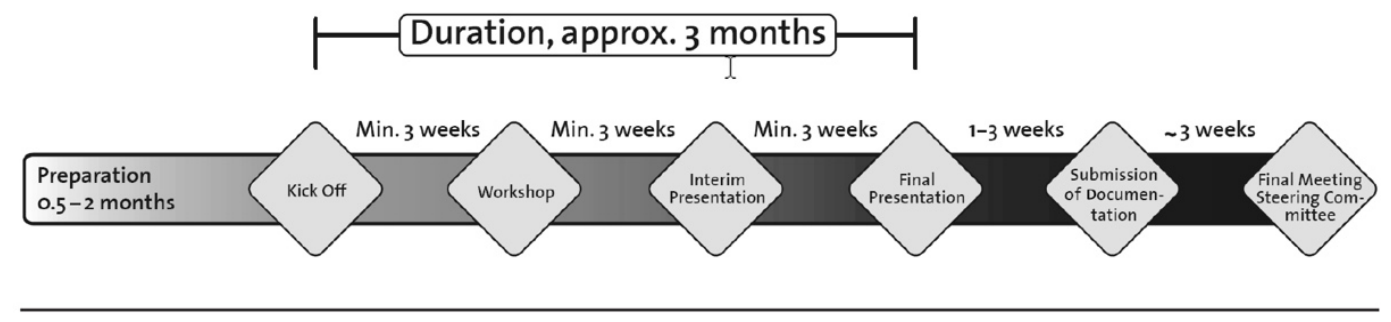

Figure 3 - Typical organisation of a test planning process (Source: ARL 2011 in Scholl 2017).

As to the structure of the process (Fig. 2), the role of each group is, in brief, as follows (Scholl 1995, 2017):

Executive Representatives from politics and entrepreneurs: The Executive Committee consist of two to five representatives (all with voting rights) of the commissioning political authorities and organizations. It distributes the formal mission for conducting a test planning process, is regularly informed about the working progress of the Steering Committee, and approves the definitive recommendations resulting from the test planning process. The Executive Committee also selects the coordinating chairman from within its members.

Steering Committee: The Steering Committee comprises usually seven to twelve persons (all with voting rights), who are experts from the commissioning body as well as independent experts. Additional experts, without voting rights, can be also invited. The Steering Committee leads the test planning process content-wise, is in direct discussion with the 
planning teams, and formulates the recommendations from the team proposals to submit them later to the Executive Committee, while it selects the coordinating chairman from its members, usually based on the suggestion of the Executive Committee.

Planning Teams: A minimum of three, maximum four, interdisciplinary teams work on problem-solving proposals to address the problems presented in the task description (Task Mission), which is the same for all teams. The selection of the teams should provide a diversity of qualified teams from the region, and elsewhere, national or international. A prequalification phase can support the selection.

Steering Committee's Office and the Preparation Group: The Steering Committee has an office assigned to it, responsible for writing up the protocols, performing other tasks, and organising the meetings, as well as the preliminary assessments and synopses of the team proposals for the final meeting. In addition to the Office, during the preparation phase of a test planning process, a Preparation Group is required. This group is responsible for the compilation and preparation of the basic information on the test planning task description, the preliminary assessment of the projects and the operative leadership of the process.

The Test Planning Process is rooted in the case of the Vienna Model (1975), Vienna's need of flood protection for the Danube River, while it has been implemented in several other cases such as Frankfurt's regeneration of the urban area along the Main River waterfront (Stadtraum Main), the Swiss cases of Solothurn's revitalization of one of the largest brownfields, the transformation of the abandoned military airport at Dübendor, the case of Brig Railway Station, or the brownfield regeneration of Bovisa Gasometri in Milan (Scholl 2017). In those cases, besides the previously described steps and role models, two more elements contributed significantly in the impact if informal planning; the formulation of the conciliums, e.g. in the case of Vienna and Frankfurt, or the formulation of platform associations, e.g. in the cases of the Limmat Valley and Brig. The role of the concilium concentrated on preparing the ground for a common discussion before, during and after the implementation of an informal planning process. Likewise, the composition of platform associations, consisted of representatives of the stakeholders, was a result of informal planning and it supported the following formal planning processes, creating common ground for exchange knowledge and information among the actors and the public.

How well do the elements of the TPP incorporate the principles of collaborative rationality? Figure 4 offers a graphic image detailing important overlaps. 


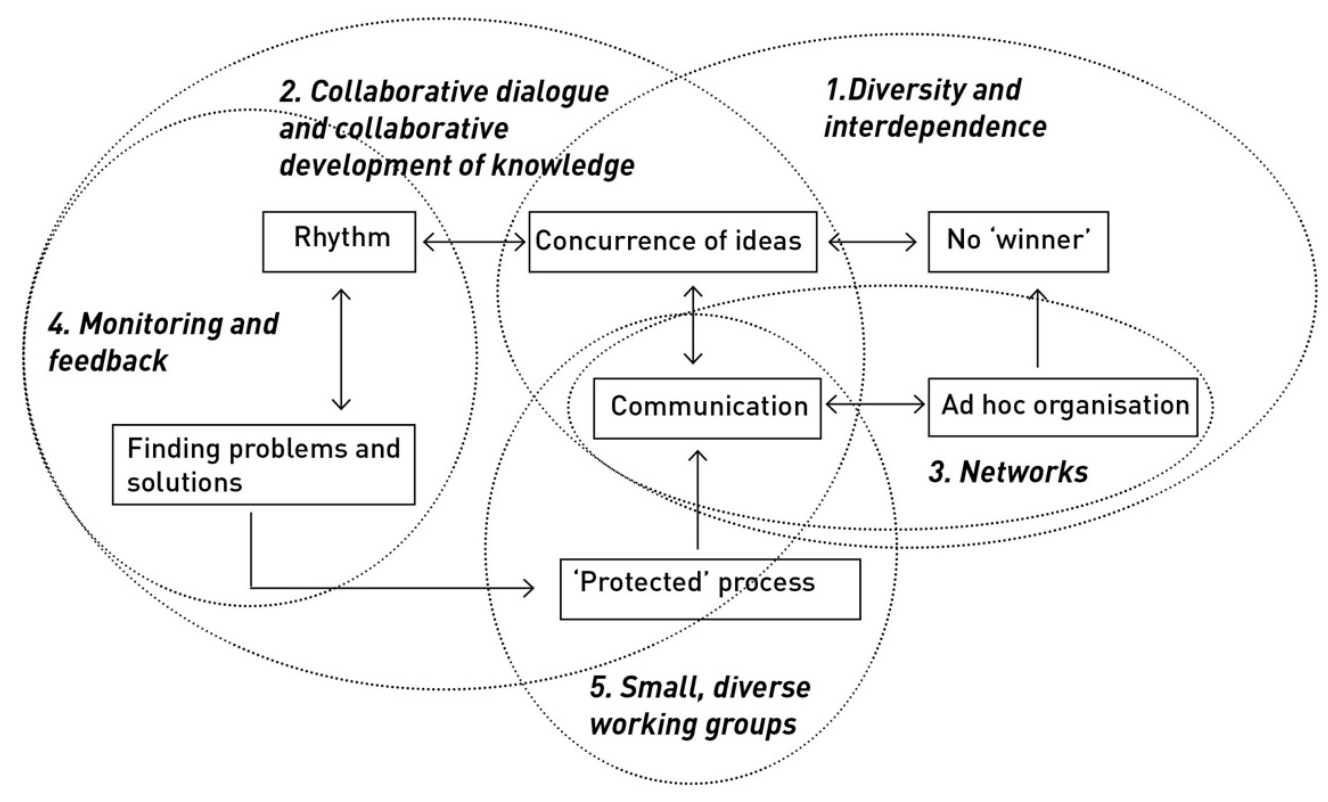

Figure 4 - The interrelation between five principles of collaborative rationality and seven principles of the test planning process (Source: Papamichail and Perić 2018).

\section{Towards adaptive urban governance through informal planning?}

Based on the interrelation of informal planning and collaborative rationality, the five principles are following (Papamichail, 2019):

- Inclusive, flexible \& transparent processes towards joint responsibility. They increasing security for the process based on trust building, eliminating misconceptions, and managerial relations or 'behind the scenes' actions. Furthermore, it includes all responsible actors and overcomes administrative and institutional borders as well as adapts to tasks of different spatial (national, regional, local) and power (national, regional, local) scales and projects (brownfield regeneration, transport development etc.), creating new spaces for action.

- Non-linear, but simultaneous processes based on the three-cycle design. They provide knowledge as to how to act simultaneously at the right moment, dealing with various aspects of sustainable development, accelerating decision-making saving time and funding resources. Such processes stimulate a spectrum of problem-oriented solutions that are not often visible or commonly accepted in the beginning, and offer both purposeful criticism and the time to come up with robust ideas and solutions.

- Focus on public consensus building. Based on collaborative dialogue, informal planning not only produces agreements and plans, but it also enacts experimentation, learning, change, and building shared meaning among all affected parties. This counterbalances hierarchical and political mandates, as well as administrative procedures, which preclude the kind of conversation needed to avoid 
the pitfalls of adversarial positions and posturing. Moreover, it weakens ideological and personal commitments that usually blind officials and clients to problem complexity and adaptive solutions.

- Potential and problem-oriented scenarios and solutions. Informal planning complements with problem or potential-oriented planning scenarios and solutions based on concurrence of ideas. Unlike the usual concept of a competition, the concept of the concurrence of ideas delivers multi-functional concepts based on diverse aspects and ideas. As a result, this provides holistic plans based on commonly accepted frameworks and conditions.

- Actor networks based on role differentiation. offer diversity and interdependency between the participants based on an ad hoc and clarified structure. This structure includes a commission (representatives of executive authorities), a guiding group (which binds representatives from both public authorities and private sector) and working groups (planning teams). Not less than three different working groups ensure plurality of ideas and solutions, testing even those that have been disregarded.

Hence, the principles of informal planning contribute the following, concerning the promotion of adaptive urban governance in environments of crisis: 1) flexible and agile institutional arrangements supportive to various kinds of urban planning mechanisms (not only official tools), 2) proactive and imaginative planners ready to accept solutions created outside the technical domain of instrumental rationality, and 3) inclusion of numerous stakeholders to exchange various information and different types of knowledge, i.e. expert and experiential knowledge, 4) problem-oriented scenarios and solutions of spatial and urban development, based on the concurrence of ideas.

\section{Conclusion}

Informal planning shows how it can supplement formal planning structures and serve as a tool for adaptive urban governance. Even though, in several cases, informal planning is not accepted fully by different planning cultures, it presents a potential and long-term impact. Namely, informal planning processes:

- Point out a step-wise development concerning complex tasks in spatial planning based on concrete arguments, which emerge through clarification processes.

- Provide shared experience to inform simultaneously formal national institutions or transnational institutions, i.e. EU institutions, policies and instruments, providing information channels among international, national, regional and local level of spatial planning.

- Include numerous stakeholders and smooth the paradoxical role of planners, who act between formal and informal responsibility.

- Provide a spectrum of action, especially in countries challenging socioeconomic environments, and it might happen opening the door for further research. 
Reinforcing strategic decision-making and a step-wise development are the tools for paving the way towards a new planning culture. Nevertheless, changing planning culture is a longterm process, which may or may not be successful. This does not depend only on planners and their readiness to understand, accept new skills and adapt these to the local settings, but it depends more on the general socioeconomic conditions, which provide a secure and stable context for innovative planning to happen. For instance, the adoption and interpretation of informal planning in countries with immature society in collaborative planning processes, e.g. in Greece, or no background in deliberative democracy, e.g. China, Iran, can still provide challenges regarding the misinterpretation of the role of informal planning towards favouring again fast-track investments and focusing on the benefits for a few. For creating a mature background, the systemic support is needed as a backbone, i.e. though education - only in this case planning finds a fruitful ground for interpreting and implementing informal procedures. This opens further questions for future research steps concerning the transfer of tacit knowledge in countries with partially developed culture in collaboration and deliberative democracy.

\section{References}

Allmendinger, Philip; Tewdwr-Jones, Mark (2002) Planning futures: New directions for planning theory, London: Routledge.

Briassoulis, Helen (1997) "How the others plan: Exploring the shape and forms of informal planning", Journal of Planning Education and Research, 17, 105-117.

Davidoff, Paul; Reiner, Thomas. A. (1962) "A Choice Theory of Planning”, Journal of the American Institute of Planners, 28:2, 103-115.

Faludi, Andreas (1973) Planning theory (Vol. 7, Urban and regional planning series). Oxford etc.: Pergamon.

Flyvbjerg, Bent (1998) Rationality and power: Democracy in practice (Morality and society). Chicago: University of Chicago Press.

Forester, John (1999) The deliberative practitioner, encouraging participatory planning processes. Cambridge, MA: MIT Press.

Habermas, Jürgen (1984) The theory of communicative action. Vol 1. Reason and the rationalizations of the society, London: Heineman.

Healey, Patsy (1992) Planning through Debate: The Communicative Turn in Planning Theory. Town Planning Review, 63, 143-162.

Healey, Patsy (1997) Collaborative planning - Shaping places in fragmented societies. London: MacMillan Press.

Heskin, Allan, David (1980) “Crisis and Response: A Historical Perspective on Advocacy Planning", Journal of the American Planning Association, 46:1, 50-63. 
Hoch, C.1994. What Planners Do: Power, Politics, and Persuasion. Chicago, Illinois etc.: Planners Press.

Hoch, Charles; Scholl, Bernd (2018) Linking Informal and Formal Responsibility. In: Peric, A., Signer, R. (eds), "Spatial Planning Matters! Inspiring topics and fundamental topics." Zurich: vdf Hochschulverlag AG.

Innes, Judith (1995) "Planning theory's emerging paradigm: Communicative action and interactive practice", Journal of Planning Education and Research, 14:138-196.

Innes, Judith (1996) "Planning through Consensus building. A new view of the comprehensive planning". Journal of American Planning Association, vol. 62, issue 4.

Innes, Judith; Booher, David (2010) Planning with complexity: An introduction to collaborative rationality for public policy, New York: Routledge.

Lubell, Harrold (1991) The Informal Sector on the 1980s and 1990s. Paris, France: Development Centre of the Organisation for Economic Cooperation and Development.

Meyerson, M.; Banfield E.C. 1964. Politics, Planning, and the Public Interest: The Case of Public Housing in Chicago. A Free Press Paperback. London: Free Press of Glencoe.

Muller, Jerry Z. (1993) Adam Smith in his time and ours: Designing the decent society, New York: Free Press.

Papaioannou, Athanasios; Nikolakopoulou, Christina (2016) Greek cities in crisis: Context, evidence, response. In Jörg Knieling and Frank Othengrafen (Eds.), "Cities in crisis: Socio-spatial impacts of the economic crisis in Southern European cities" (pp. 172189), New York: Routledge.

Papamichail, Theodora (2015) "Railway and urban development in Patras: Towards the improved participation of local governance in complex planning problems". Serbian Architectural Journal, 7(3), 365-380.

Papamichail, Theodora; Perić, Ana (2018) "Informal Democracy in Patras, Greece: A Mechanism for Improved Planning?", Cities, 74: 334-42.

Papamichail, Theodora (2019) Spatial Synergies. Synergies between formal and informal planning as a key concept towards spatial conflicts - the case of tourism-oriented railway development in the Peloponnese, Dissertation (accepted by the examiners, 4.7.2019), ETH Zurich Research Collection (forthcoming).

Perić, Ana; Soltaniehha, Mahdokht (2015) Expert Advisory Platforms: A Critical Analysis of Collaborative Planning Procedures. In Scholl, Bernd; Dubbeling, Martin; Perić, Ana (eds)" "Ten Years of UPATs. Reflections and results", Zurich: vdf Hochschulverlag AG.

Rittel, Horst; Webber, Melvin (1973) "Dilemmas in a General Theory of Planning." Policy Sciences 4: 155-69.

Sager, Tore (1994) Communicative Planning Theory, Aldershot: Avebury. 
Sandercock, Leonie (1998) Towards cosmopolis: Planning for multicultural cities. Chichester: Wiley.

Scholl, Bernd (1995) Aktionsplanung. zur Behandlung komplexer Schwerpunktaufgaben in der Raumplanung, Zürich. vdf-Hochschulverl. an der ETH.

Scholl, Bernd; Staub, Bernard; Vinzens, Martin (Eds.) (2013) Test planning - A method with a future, Zurich: vdf Verlag.

Scholl, Bernd, et al. (2015) Code Patras - Rail \& city - A test planning process for Patras. Zurich: ETH Zurich, Institute for Spatial and Landscape Development.

Scholl, Bernd (2017) "Building Actor Relationships and Alliances for Complex Problem Solving in Spatial Planning: The Test Planning Method", disP - The Planning Review, 53:1, 4656.

Scholl, Bernd; Staub, Bernard; Vinzens, Martin (Eds.) (2013) Test planning - A method with a future, Zurich: vdf Verlag.

Schönwandt, Walter (2008) Planning in crisis? Theoretical orientations for architecture and plannin, Ashgate: Aldershot.

Sorensen, A. D. (1983) "Towards a Market Theory of Planning", The Planner, 69, 3: 78-80.

Zifou, Maria (2015) Greek spatial planning and the crisis. In Frank Eckardt, \& Javier Ruiz Sanchez (Eds.) "City of crisis: The multiple contestation of Southern European cities" (pp. 155-178), Bielefeld: Transcript Verlag. 